\title{
Oral lesions frequency in HIV-positive patients at a tertiary hospital, Southern Brazil
}

\author{
Cristiane Pedroso Peppes ${ }^{1}$, Ana Silvia Pavani Lemos ${ }^{1}$, Renata Lins Fuente Araujo ${ }^{1}$, \\ Magda Eline Guerrart Portugal ${ }^{1}$, Marilene da Cruz Magalhães Buffon', Sonia Mara Raboni'
}

${ }^{1}$ Federal University of Paraná, Curitiba, PR, Brazil

Received for publication: May 15, 2013

Accepted: September 11, 2013

Correspondence to: Sonia Mara Raboni

Serviço de Infectologia, Hospital de Clínicas da Universidade Federal do Paraná

Rua General Carneiro 180, $3^{\circ}$ andar CEP: 800060-900 - Curitiba, PR, Brasil

Fax: +554133601811

Phone: +554133607974

E-mail: sraboni@ufpr.br

raboni.sonia@gmail.com

\section{Abstract}

Aim: To report the frequency of oral lesions in HIV-positive patients on Highly Active Antiretroviral Therapy (HAART), comparing with a non-HIV infected control group, and to correlate the presence of lesions with demographic and clinical features of HIV-seropositive patients. Methods: A quantitative case-control study was conducted by a dental professional, using a questionnaire, analysis of medical records of patients and clinical examinations. Results: According to the results, oral lesions were found in $23 \%$ of HIV-positive patients versus $5 \%$ in controls. Candidiasis $(29 \%)$ and periodontal changes $(25 \%)$ were the most frequent oral lesions found in these patients. Gender and viral load values were statistically significant when HIV-positive patients with and without oral lesions were compared. Conclusions: The results showed a change in lesion pattern of HIV patients on HAART, highlighting a high frequency of these new lesions and reinforcing the need for periodic dental evaluation of HIV-positive patients.

Keywords: HIV, bacterial infections, candidiasis, opportunist infections.

\section{Introduction}

AIDS has been a serious worldwide public health threat, with a global prevalence in 2010 of about 34 million and an overall number of AIDS-related deaths of 1.8 million of people. In Brazil up to the end of 2011, 608,200 cases were notified, 397,662 (65.4\%) in males and 210,538 (34.6\%) in females. Currently, investments in prevention, scaling up access to HIV testing and to antiretroviral treatment, as well as training of health professionals, keep the AIDS epidemic under control ${ }^{1}$.

According to the Brazilian Ministry of Health, the prevalence of the disease in 2011 remained stable at around 0.6\%, while the incidence was 17.9/100,000 inhabitants. In the state of Paraná, Southern Brazil, 32,273 cases were reported in the same period, with an incidence of 19/100,000 inhabitants. The Southern region ranks third in the number of AIDS cases in Brazil, with 21.1\% of cases, after the Southeast (38.2\%) and Northeast (21.7\%). Nevertheless, this is the region where the largest number of new cases were detected in 2009, with a detection rate of $12.6 / 100,000$ inhabitants ${ }^{1}$.

Oral manifestations are frequently seen during the course of the disease and can be symptoms of early HIV infection. With their immune system severely compromised by HIV infection, patients are vulnerable to opportunistic infections and cancers, particularly oral lesions such as oral candidiasis, Kaposi's sarcoma, 
sores, gingivitis, periodontitis and herpes lesions. The emergence of these lesions is associated with immunodeficiency, and they are often the first symptom of AIDS or an indication of worsening of disease. HIV patients with associated oral lesions often complain of chewing problems, burning sensation, and difficulty in swallowing and speech among others, which has a negative impact on their quality of life $\mathrm{e}^{2-4}$. A wide spectrum of oral manifestations may occur in these patients dependent on factors such as degree of immune impairment, use of antiretroviral therapy, oral hygiene, among others 5 .

Since these oral manifestations associated to the progression of HIV infection are common and may be the first clinical signs of disease, the dentist has a very important role in detecting and diagnosing the disease in its earliest stages and in providing appropriate treatment to the patient ${ }^{6}$.

Oral manifestations in HIV-positive patients have been the subject of many studies in the pre-HAART era. These studies have become less frequent after the introduction of the HAART. The aims of this study are to report the frequency of oral lesions in HIV patients on HAART, compared with a non-HIV infected control group and correlate the lesion with demographic and clinical features of HIV-seropositive patients.

\section{Material and methods}

\section{Study Design}

A cross-sectional study was conducted from November 2009 through November 2010 on HIV-positive patients followed at the Infectious Diseases Service at Hospital de Clínicas, Universidade Federal do Paraná (HC/UFPR). The study was approved by the Ethics Committee in Research on Human Beings of the HC/UFPR under protocol number 1943.110/2009-05.

\section{Casuistic}

The HIV-positive patients and a control group were included in the study after providing written informed consent. A questionnaire was used to collect clinical data based on the analysis of the medical records, obtain demographic and behavioral information provided by the patient and report clinical examinations performed by one dentist using a visual examination method.

To select the control group, the authors conducted a search on clinics that offered free dental treatment, such as clinics of trade unions for care workers, which presented socioeconomic level and educational instruction similar to the HIV-positive patients. Subjects were randomly invited to participate in the study, and those who accepted and signed the informed consent were examined. From 596 individuals analyzed, 208 that met the criteria for median age similar to the patients of the study groups and previous negative HIV antibody test within 6 months were included as controls. The questionnaire applied to this group was similar to the one used in the study group.

\section{Sample Size Calculation}

Sample size calculation was based on the following estimates: $\alpha$ error of $0.05 ; \beta$ error $=0.20$ ( $80 \%$ power). For the purposes of these calculations the prevalence of oral lesion in HIV + patients was arbitrarily set at $15 \%$ and in control group at $5 \%$. Considering that the number of HIV + treated at this hospital is around 1,000, the finite population correction factor was used to reduce the standard error. Incorporating these estimates into the equation yields a sample size of 164 , assuming a $20 \%$ loss, at least 197 were required per group.

\section{Statistical analysis}

Descriptive analysis was performed for all variables. Data were compiled using the JMP software version 5.2.1 and analyzed by the GraphPad Prism software version 5.03. Fisher's exact or $\div 2$ tests were used to assess differences between groups and Mann Whitney test was used for continuous variables, as appropriate. Results of continuous data are expressed as median \pm interquartile range (IQR). All P-values were two-tailed and a value of $<0.05$ was considered significant.

\section{Results}

A total of $241 \mathrm{HIV}$-positive patients and 208 control individuals were enrolled in the study. The control group showed a similar profile to the study group with relation to age and years of education. The median age of the patients was 41 and 36 years for HIV-positive and control group, respectively, and $63 \%$ of HIV-positive individuals and $60 \%$ of controls had between 4 and 11 years of education. Other demographic and epidemiological findings are shown in Table 1.

HIV-positive patients had been diagnosed with HIV infection for an average of $8.4( \pm 4.9)$ years and presented a median of nadir and current CD4 $+\mathrm{T}$ lymphocyte count of 276.5 cells $/ \mathrm{mm}^{3}$ (IQR, 123.3-502.3) and 426 cells $/ \mathrm{mm}^{3}$ (IQR, 264-630), respectively. Most patients (78.6\%) were on HAART and in 167 cases (69\%) viral load was undetectable. Among those with detectable viral load, the median was 3,737 copies/mL (IQR 558 - 26,267), 20.3\% had < 10,000 copies/ $\mathrm{mL}, 7 \%$ had between 10,000 and 100,000 copies $/ \mathrm{mL}$, and only $2.9 \%$ of patients had more than 100,000 copies $/ \mathrm{mL}$.

Oral lesions were found in 56/241 (23\%) of HIV-positive patients versus $10 / 208(5 \%)$ in controls $(\mathrm{p}<0.001)$. As shown in Figure 1, the most frequent lesions in HIV-positive patients were candidiasis and periodontal changes, while herpes lesions were more common in the control group, which was found in 3.5\% (2/56) of HIV-positive patients and in $80 \%$ $(8 / 10)$ of control group. Idiopathic white patch and ulcerations of oral mucosa were observed in $23 \%$ and $5 \%$ of HIV-positive patients, respectively.

Comparison between HIV-positive patients with and without lesion showed that they had similar clinical characteristics, except for gender and viral load values that showed statistically significant differences (Table 2). There was a predominance of male patients with lesions $(\mathrm{p}=0.03)$, 
Table 1. Demographic and epidemiological characteristics of HIV-positive patients and control group individuals

\begin{tabular}{|c|c|c|c|}
\hline & $\begin{array}{c}\text { HIV-positive } \\
\text { patients } \\
\mathrm{N}=241\end{array}$ & $\begin{array}{l}\text { Control group } \\
\qquad N=208\end{array}$ & $p$ value \\
\hline \multicolumn{4}{|l|}{ Gender (\%) } \\
\hline Male & $102(42)$ & $114(55)$ & 0.008 \\
\hline Female & $139(58)$ & $94(45)$ & \\
\hline \multicolumn{4}{|l|}{ Age (y) } \\
\hline Median (IQR) & $41(32-48)$ & $36(28-43)$ & 0.0012 \\
\hline \multicolumn{4}{|l|}{ Race (\%) } \\
\hline White & $140(58)$ & $138(66)$ & 0.07 \\
\hline Brown & $77(32)$ & $62(30)$ & \\
\hline Black & $22(9)$ & $8(4)$ & \\
\hline Yellow & $1(0.5)$ & - & \\
\hline$\underline{\mathrm{NI}}$ & $1(0.5)$ & & \\
\hline \multicolumn{4}{|l|}{ Marital status (\%) } \\
\hline Married & $82(34)$ & $122(58.5)$ & $<0.0001$ \\
\hline Single & $158(65.5)$ & $67(32.5)$ & \\
\hline Divorced & - & $19(9)$ & \\
\hline $\mathrm{NI}$ & $1(0.5)$ & - & \\
\hline \multicolumn{4}{|l|}{ Sexual behavior (\%) } \\
\hline MSM & $15(6)$ & $11(5)$ & $<0.0001$ \\
\hline Heterosexual & $107(45)$ & $197(95)$ & \\
\hline Bisexual & $7(3)$ & 0 & \\
\hline$\underline{\mathrm{NI}}$ & $112(46)$ & 0 & \\
\hline Other Risk factors & & & - \\
\hline IDUs & $8(3)$ & 0 & \\
\hline Blood transfusion or clotting factor & $7(3)$ & 0 & \\
\hline Occupational Exposure & $3(1)$ & 0 & \\
\hline$\underline{\mathrm{NI}}$ & $92(38)$ & Not applicable & \\
\hline \multicolumn{4}{|l|}{ Years of education (\%) } \\
\hline $1-3$ & $23(10)$ & $3(1) 64$ & 0.0003 \\
\hline $4-7$ & $82(34)$ & $(31) 81$ & \\
\hline $8-11$ & $70(29)$ & (39)59 & \\
\hline$>12$ & $57(23)$ & $(28.5) 1$ & \\
\hline None & $7(3)$ & $(0.5)$ & \\
\hline$\underline{\mathrm{NI}}$ & $2(1)$ & - & \\
\hline \multicolumn{4}{|l|}{ Tooth brushing habits (\%) } \\
\hline $1 x d a y$ & $19(8)$ & $3(2)$ & 0.001 \\
\hline $2 x d a y$ & $76(31)$ & $58(28)$ & \\
\hline $3 x d a y$ & $142(59)$ & $147(70)$ & \\
\hline$\underline{\mathrm{NI}}$ & $4(2)$ & - & \\
\hline \multicolumn{4}{|l|}{ Smoking (\%) } \\
\hline Yes & $62(25.5)$ & $28(13)$ & 0.0013 \\
\hline No & $178(74)$ & $180(87)$ & \\
\hline $\mathrm{NI}$ & $01(0.5)$ & - & \\
\hline
\end{tabular}

the median values of nadir and current $\mathrm{CD} 4+\mathrm{T}$ lymphocyte detection were 221(67.3 - 451.8) cells $/ \mathrm{mm}^{3}$ and 293(147.5 $502.5)$ cells $/ \mathrm{mm}^{3}, 64 \%$ and $61 \%$ had undetectable load viral and median values of viral load were $9,144(693-78,321)$ copies $/ \mathrm{mL}$ and 3,018 $(553-17,293)$ copies $/ \mathrm{mL}(\mathrm{p}=0.02)$, respectively.

\section{Discussion}

The spread of HIV infection in Brazil has revealed an epidemic of multiple dimensions, with a significant change in the epidemiological profile over the years, following the global trend. Initially restricted to large urban centers and 
Table 2. Clinical, epidemiological and demographic data from HIV-positive patients with and without oral lesions

\begin{tabular}{|c|c|c|c|}
\hline & $\begin{array}{l}\text { HIV-positive patients } \\
\text { with oral lesions } \\
\qquad N=56\end{array}$ & $\begin{array}{l}\text { HIV-positive patients } \\
\text { without oral lesions } \\
\qquad N=185\end{array}$ & $p$ value \\
\hline \multicolumn{4}{|l|}{ Age (y) } \\
\hline Median (IQR) & $43(32-50)$ & $41(32.2-48)$ & 0.35 \\
\hline \multicolumn{4}{|l|}{ Gender } \\
\hline Male/female & $31 / 25$ & $71 / 114$ & 0.02 \\
\hline \multicolumn{4}{|l|}{ Years of study (\%) } \\
\hline $1-3$ & $9(16)$ & $14(7.5)$ & 0.08 \\
\hline $4-7$ & $21(38)$ & $61(33)$ & \\
\hline $8-11$ & $14(25)$ & $56(30.5)$ & \\
\hline$>12$ & $8(14)$ & $49(26.5)$ & \\
\hline None & $3(5)$ & $4(2)$ & \\
\hline $\mathrm{NI}$ & $1(2)$ & $1(0.5)$ & \\
\hline \multicolumn{4}{|l|}{ Smoking (\%) } \\
\hline Yes & $17(30)$ & $45(24.5)$ & 1.00 \\
\hline No & $39(70)$ & $139(75)$ & \\
\hline$\underline{\mathrm{NI}}$ & - & $1(0.5)$ & \\
\hline \multicolumn{4}{|l|}{ Nadir CD4+ T-cells } \\
\hline \multicolumn{4}{|l|}{ count } \\
\hline${ }^{*}$ Median (IQR) & $221(67.3-451.8)$ & $293(147.5-502.5)$ & 0.36 \\
\hline \multicolumn{4}{|c|}{ Current CD4+ T-cells count } \\
\hline${ }^{*}$ Median (IQR) & $390(264-540.3)$ & $447(310-639)$ & 0.57 \\
\hline \multicolumn{4}{|l|}{ Viral load** } \\
\hline$\leq 50$ copies $/ \mathrm{mL}(\%)$ & $26(46)$ & $131(71)$ & 0.23 \\
\hline Median (IQR) & $9.144(693-78.321)$ & $3.018(553-17.293)$ & 0.02 \\
\hline \multicolumn{4}{|l|}{ HAART (\%) } \\
\hline Yes & $45(80)$ & $144(78)$ & 0.84 \\
\hline No & $11(20)$ & $41(22)$ & \\
\hline
\end{tabular}

markedly masculine, the HIV/AIDS epidemic is currently characterized by an increase in heterosexual transmission, with a substantial increase in number of cases among women and injecting drug users, spread of disease to small and midsized cities, and pauperization of the infected population ${ }^{7}$.

Since 1996 Brazil has provided free antiretroviral drugs to all patients with HIV/AIDS, according to a guideline for the use of antiretroviral agents in HIV-1 infected adults and adolescents. The consolidation of the care policy for people living with HIV in Brazil has produced considerably positive results. Until 2005, AIDS-related mortality rate was reduced by almost $40 \%$ and the median survival rate of people living with HIV increased from 58 months in 1995-1996 to 108 months in 1998-19998.

The availability of antiretroviral drugs on a large-scale has contributed to reduce the frequency and change the pattern of oral manifestations, and, thus, many complaints tended to be overlooked by healthcare professionals. Also, the causes of oral diseases in HIV-positive patients were little investigated. This study showed a higher frequency of oral lesions in HIV-positive patients compared with the control group, highlighting the importance of oral clinical examination of these patients, as well as of detection and diagnosis of HIV in patients with these symptoms by the dentist.

The success or failure of antiretroviral therapy is assessed by viral load and CD4 $+\mathrm{T}$ lymphocytes count. Undetectable viral load indicates a strong control of viral replication and, therefore, reduced damage to the immune system ${ }^{4}$. This study showed that $69.3 \%$ of patients had undetectable viral load, which shows the success of therapy in most patients.

Of all the patients with oral lesions, $80 \%$ (45/56) were on regular treatment and 20\% (11/56) were not on HAART. In both groups, periodontal changes were the most common lesions followed by oral candidiasis and idiopathic white patch or leukoplakia, which is an area of keratosis that appears as adherent white spots on the mucous membranes of the oral cavity. It consists predominantly in white lesion of the oral mucosa that cannot be characterized as any other definable lesion. Therefore, there was no statistical difference in the prevalence of oral manifestations or in the distribution of lesions between patients on HAART and those not on HAART. The prevalence of oral lesions in untreated patients was similar to that found previously ${ }^{6}$, which showed that $20 \%$ of patients not on HAART had some type of oral lesion.

Likewise, Nittayananta et al. ${ }^{9}$ (2002) showed that hyperpigmentation was a very frequent lesion in patients 


\section{Oral lesions in HIV-positive patient}

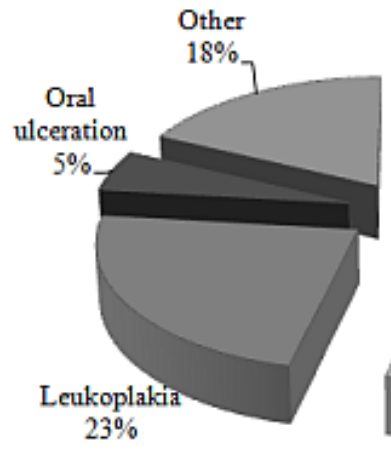

\section{Oral lesions in control group}

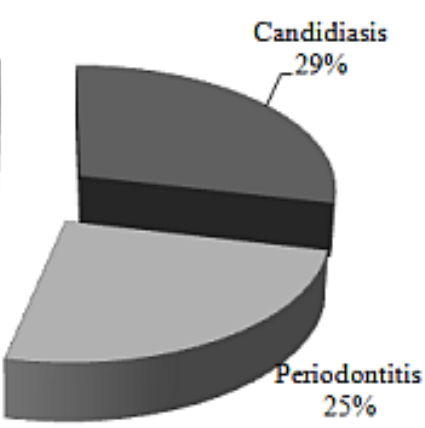

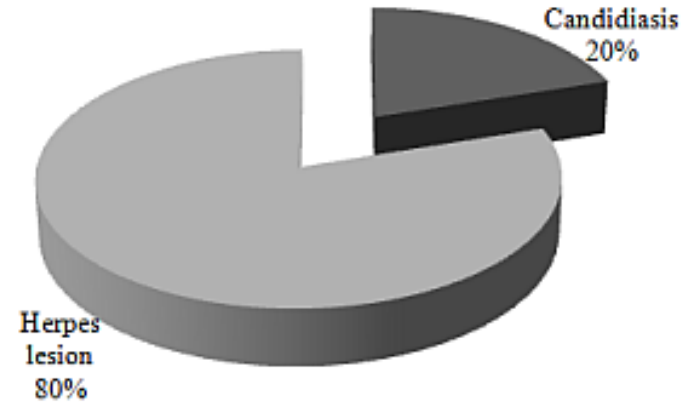

Fig. 1. Oral lesions found in HIV-positive patients $(n=56)$ and control group individuals $(n=10)$

using HAART, which was considered a consequence of zidovudine use, and compared with patients not on HAART, patients on HAART were at lower risk of caries and periodontal disease. In this study, the frequency of periodontal changes was similar in both groups, regardless of drug use.

Despite the advances represented by antiretroviral drugs, their serious side-effects may reduce the levels of patient adherence to treatment. These effects may also be associated with oral manifestations, such as sore throat, dry mouth and perioral paresthesia ${ }^{5}$, such findings were not observed in this study group.

HIV-positive patients may have decrease in the salivary flow, which can result from the viral infection or be a side effect of antiretroviral therapy. Thus, these patients may show higher caries prevalence, higher rates of periodontal disease, mucositis and opportunistic infections, as well as salivary gland lesions, that signs include swollen glands and a decrease in salivation ${ }^{5}$.

Candidiasis was the most prevalent oral manifestation in HIV-positive patients compared with the control group, $29 \%$ and $20 \%$, respectively. This infection has been widely associated with HIV infection and was present in all the reviewed articles on the prevalence of oral manifestations in these patients ${ }^{10}$. According to Shirlaw et al. ${ }^{11}$ (2002) candidiasis occurs in $50 \%$ of HIV-infected individuals and $90 \%$ of those with AIDS. In asymptomatic HIV-infected individuals it is a sign of immunosuppression and often precedes the transition to $\operatorname{AIDS}^{12}$.

Periodontal disease (PD) is an inflammatory and chronic bacterial disease, which initially affects the gingival tissues. Over time, it can lead to destruction of the tissues that support the teeth. The presence of periodontal involvement (gingivitis, periodontitis, acute necrotizing ulcerative gingivitis - ANUG and acute necrotizing ulcerative periodontitis - ANUP) is an indication that the individual's immune system is impaired, and its early recognition may impact HIV-positive patients' life quality.
Several studies show that the clinical course of chronic periodontitis is faster in HIV/AIDS patients compared with HIV-negative individuals. HIV/AIDS patients have subgingival microorganisms similar to those found in periodontal pockets of HIV-negative individuals. However, in HIV/AIDS patients there is also the presence of other opportunistic microorganism unrelated to chronic periodontitis, which may be related to the rapid development of periodontal disease. Another possible cause of periodontal destruction in HIV patients may be the increased activity of periodontal disease, as a consequence of the high levels of proinflammatory cytokines in the gingival crevicular fluid from sites with active periodontal disease ${ }^{13}$.

In this study, periodontal changes were found in $25 \%$ of the cases, while none were found in the control group. Of those patients, approximately $40 \%$ had current CD $4+\mathrm{T}$ cells counts between 200 and 500 cells $/ \mathrm{mm}^{3}$ and $46 \%$ had undetectable viral load. Mariano ${ }^{14}$ did not find significant differences between cases and controls. Similarly, other authors did not find a direct relationship between the degree of immunosuppression by HIV and the prevalence of periodontal disease, since most patients with severe periodontal disease were HIV asymptomatic ${ }^{15}$. These findings were also consistent with the study conducted by Scheutz et al. ${ }^{16}$ (1997) and Vastardis, et al. ${ }^{17}$ (2003), who did not find correlation between $\mathrm{CD} 4+\mathrm{T}$ cells count and severe periodontal disease.

Laskaris, Madjivassilion and Stratigos ${ }^{18}$ (1992) reported the difficulty of correlating periodontal disease with HIV infection, since most patients showed poor oral hygiene, high incidence of dental biofilms, often causing gingivitis and periodontitis. No significant difference was observed regarding tooth cleaning frequency between the groups. Therefore, this factor would probably not have influenced these findings.

In this study, herpes simplex infection in the lower lip was more common in control group (80\%) than in HIVpositive patients $(3.5 \%)$, similarly to Chagas, Santos and 
Ono $^{2}$ (2009), who reported herpes in $2 \%$ of cases. Studies conducted in HIV-positive patients in Nigeria ${ }^{19}$ and India ${ }^{20}$ showed that herpes simplex infection was less prevalent, accounting for $0.9 \%$ of patients. Only in Cambodia the prevalence of herpes simplex lesion was slightly higher, $7.9 \%{ }^{21}$. Challacombe, Coogan and Williams ${ }^{22}$ (2002) reported that oral herpes are not frequently associated with HIV infection, usually occurring in individuals with HIV infection who develop AIDS.

Ulcerations in the oral mucosa that are related to the immune status of the patient are observed in HIV-positive patients ${ }^{23}$. Mouth ulcers are reported in several studies in HIV-infected individuals, with variations in prevalence as seen in India $(3.8 \%)^{20}$, China $(14.8 \%)^{24}$ and England $(23 \%)^{25}$. In the present study, approximately $5 \%$ of the patients had such oral lesions, which is similar to the $7 \%$ found in the study of Chagas, Santos and $\mathrm{Ono}^{2}$ (2009).

The wide availability of HAART had a major impact on improving survival of HIV-positive patients. Moreover, a change could be seen in the pattern of the clinical disease in this group of patients. A decrease of frequency of some diseases, such as Kaposi's sarcoma was observed, but current findings demonstrate that HIV-positive patients, regardless of their response to therapy, have an increased frequency of other oral lesions, such as periodontal disease, compared with uninfected individuals ${ }^{26}$. These data reinforce the need for periodic dental evaluation. It should be included in the routine monitoring of these patients, as well as the early referral of patients with these oral lesions to specialist care.

In conclusion, after the introduction of HAART there was a significant decrease in the frequency of oral lesions on HIV + patients. However, this study shows a high prevalence of other common oral lesions in HIV/AIDS patients in comparison with individuals not carrying the virus, such as periodontal diseases and candidiasis. It reinforces the need of a multidisciplinary approach of HIV/AIDS patients attending specialized centers that include regular dental evaluations aiming at early detection of diseases and prompt treatment, contributing to a better quality of life for these patients.

\section{Acknowledgements}

We thank Luciane TF Silva for participation in data collection, Dr. Clea Elisa Ribeiro, infectious disease specialist, and Dr. Giovana Pecharki, dentist and Professor of School of Dentistry of Federal University of Paraná for their helpful discussions during the study and comments on the manuscript.

\section{References}

1. Brazil, Brazilian Ministry of Health, Division of Health Surveillance, National Program on STD/AIDS. Epidemiologic Bulletin AIDS [internet]. [Accessed 2012 Jun 28] Available from: http://aids.gov.br/publicacao/2011/ boletim_epidemiologico_2011.

2. Chagas MV, Santos LO, Ono LM. Oral manifestations in HIV patients treated at the Tropical Medicine Foundation of Amazonas (FMT-AM). Rev Fac Odontol Porto Alegre. 2009; 50: 10-13.
3. Perera M, Tsang PC, Samaranayake L, Lee MP Prevalence of oral mucosal lesions in adults undergoing highly active antiretroviral therapy in Hong Kong. J Investig Clin Dent. 2012; 3: 208-14.

4. Watanuki F. Oral manifestations associated with HIV after 30 years of the epidemic in Brazil [dissertation]. São Paulo, SP, BR: Faculty of Dentistry, University of São Paulo; 2010. 115 p.

5. Tamí-Maury IM, Willig JH, Jolly PE, Vermund S, Aban I, Hill JD, et al. Prevalence, incidence, and recurrence of oral lesions among HIV-infected patients on HAART in Alabama: a two-year longitudinal study. South Med J 2011; 104: 561-6.

6. Khatibi M, Moshari AA, Jahromi ZM, Ramezankhani A. Prevalence of oral mucosal lesions and related factors in $200 \mathrm{HIV}+/$ AIDS Iranian patients. J Oral Pathol Med. 2011; 40: 659-64.

7. Dias CF, Nunes CC, Freitas IO, Lamego IS, Oliveira IM, Gilli S, et al. High prevalence and association of HIV-1 non-B subtype with specific sexual transmission risk among antiretroviral naïve patients in Porto Alegre, RS, Brazil. Rev Inst Med Trop Sao Paulo. 2009; 51: 191-6.

8. Brazil. HIV, AIDS and Viral hepatitis Department. [internet]. [Accessed 2012 Jun 21] Available from: http://www.aids.gov.br/aids.

9. Nittayananta W, Chanowanna N, Winn T, Silpapojakul K, Rodklai A, Jaruratanasirikul $\mathrm{S}$, et al. Co-existence between oral lesions and opportunistic systemic diseases among HIV-infected subjects in Thailand. J Oral Pathol Med. 2002; 31: 163-8.

10. Chopra S, Arora U. Skin and Mucocutaneous Manifestations: Useful Clinical Predictors of HIV/AIDS. J Clin Diagn Res. 2012; 6: 1695-8.

11. Shirlaw PJ, Chikte U, MacPhail L, Schmidt-Westhausen A, Croser D, Reichart $P$. Oral and dental care and treatment protocols for the management of HIV-infected patients. Oral Dis. 2002; 8: 136-43.

12. Patton LL, Ramirez-Amador V, Anaya-Saavedra G, Nittayananta W, Carrozzo M, Ranganathan K. Urban legends series: oral manifestations of HIV infection. Oral Dis. 2013; 3: 1-18

13. Mataftsi M, Skoura L, Sakellari D. HIV infection and periodontal diseases: an overview of the post-HAART era. Oral Dis. 2011; 17: 13-25.

14. Mariano BMF. Periodontal disease and oral lesions in the population HIV / AIDS referral center, control and treatment of the Military Police of Minas Gerais [dissertation]. Minas Gerais, MG, BR: Federal University of Minas Gerais; 2008. 169 p.

15. Alpagot T, Duzgunes N, Wolff LF, Lee A. Risk factors for periodontitis in HIV patients. J Periodont Res. 2004; 39: 149-57.

16. Scheutz F, Matee MI, Andsager L, Holm AM, Moshi J, Kagoma C, et al. Is there an association between periodontal conditions and HIV infection? J Clin Periodontol. 1997; 24: 580-7.

17. Vastardis SA, Yukna RA, Fidel PL Jr, Leigh JE, Mercante DE. Periodontal disease in HIV-positive individuals: association of periodontol indices with stages of HIV disease. J Periodontol. 2003; 74: 1336-41.

18. Laskaris $G$, Madjivassilion M, Stratigos J. Oral signs and symptoms in a 60 Greek HIV infected patients. J Oral Pathol Med. 1992; 21: 120-3.

19. Adurogbangba MI, Aderinokun GA, Odaibo GN, Olaleye OD, Lawoyin TO. Oro-facial lesions and CD4 counts associated with HIV/AIDS in an adult population in Oyo State, Nigeria. Oral Dis. 2004; 10: 319-26.

20. Sharma G, Pai KM, Suhas S, Ramapuram JT, Doshi D, Anup N. Oral manifestations in HIV/AIDS infected patients from India. Oral Dis. 2006; 12: $537-42$.

21. Bendick C, Scheifele C, Reichart PA 2002. Oral manifestations in 101 Cambodian patients with HIV infection and AIDS. J Oral Pathol Med. 2002; 31: 1-4.

22. Challacombe SJ, Coogan NN, Williams DN. Overview of the fourth international workshop on the oral manifestations of HIV infection. Oral Dis. 2002; 8: 9-14.

23. Owotade FJ, Shiboski CH, Poole L, Ramstead CA, Malvin K, Hecht $\mathrm{FM}$, et al. Prevalence of oral disease among adults with primary HIV infection. Oral Dis. 2008; 14: 497-9.

24. Zhang X, Reichart PA, Song Y. Oral manifestations of HIV/AIDS in China: a review. J Oral Maxillofac Surg. 2009; 13: 63-8. 
25. Eyeson JD, Tenant-Flowers M, Cooper DJ, Johnson NW, Warnakulasuriya KA. Oral manifestations of an HIV positive cohort in the era of highly active anti-retroviral therapy (HAART) in South London. J Oral Pathol Med. 2002; 31: 169-74.

26. Yengopal V, Naidoo $S$. Oral lesions associated with HIV affect quality of life? Oral Surg, Oral Med, Oral Pathol, Oral Radiol Endod. 2008; 106: 66-73. 